\title{
Lapurdum
}

Euskal ikerketen aldizkaria | Revue d'études basques |

Revista de estudios vascos | Basque studies review

$8 \mid 2003$

Numéro VIII

\section{Jurgi Kintana Goiriena : Vizcaytik Bizkaira ? R.M. Azkue Euskaltzaindia sortu aitzin (1888-1919)}

\section{Manex Goyhenetche}

\section{OpenEdition}

\section{Journals}

Édition électronique

URL : http://journals.openedition.org/lapurdum/1115

DOI : 10.4000/lapurdum. 1115

ISSN : 1965-0655

Éditeur

IKER

Édition imprimée

Date de publication : 1 novembre 2003

Pagination : $525-527$

ISBN : 9782867813436

ISSN : $1273-3830$

Référence électronique

Manex Goyhenetche, « Jurgi Kintana Goiriena : Vizcaytik Bizkaira ? R.M. Azkue Euskaltzaindia sortu aitzin (1888-1919) », Lapurdum [En ligne], 8 | 2003, mis en ligne le 01 juin 2009, consulté le 21 septembre 2020. URL : http://journals.openedition.org/lapurdum/1115; DOI : https://doi.org/10.4000/ lapurdum. 1115 


\section{Manex Goyhenetche}

\section{Compte rendu de lecture}

Jurgi Kintana Goiriena: Vizcaytik Bizkaira? R.M. Azkue Euskaltzaindia sortu aitzin (1888-1919).

Le travail de Jurgi Kintana (désormais Y.K.) est à marquer d'une pierre blanche car il contribue à éclairer une période riche et complexe, à cheval entre le $\mathrm{XIX}^{\mathrm{e}}$ et le $\mathrm{XX}^{\mathrm{e}}$ siècle. Il s'agit d'une œuvre majeure, rédigée et publiée en basque. Son lectorat est de ce fait restreint. Aussi l'ouvrage mériterait une traduction dans une langue de plus grande extension qui permettrait aux universitaires et autres non bascophones de renouveler la connaissance d'une période sur laquelle pèsent souvent approximations et généralisations hâtives. Il est vrail que Y.K. est historien et qu'à ce titre il fait montre d'une très grande rigueur dans la collecte et le traitement des documents.

L'objet de l'ouvrage, qui est la reprise remaniée de la thèse de Y.K., porte sur l'œuvre de Resurrecion Maria Azkue (R.M. A. désormais) de 1888 à 1919 , c'est-à-dire sur les trente premières années de sa vie, tellement celleci a été féconde.

La jeunesse de R.M. A. se déroula dans une période charnière pour le Pays Basque après la fin de la deuxième guerre carliste et la suppression des fueros en 1876. Y.K. restitue l'ambiance politique, culturelle, mentale de ces années, démystifie certaines affirmations non contrôlées jusqu'ici. C'est ainsi que l'on apprend que R.M.A. prit très tôt ses distances avec le nationalisme de Sabino Arana, au nom d'une vision moderne du Pays Basque qu'il résume dans cette phrase: "Mi Patria no es Euzkadi. Mi Patria se llama Euskalerria (...) Euskalerria el país del vascuence" (p. 26).

R.M. A. vécut dans une période de conflits et d'altérations de la société biscayenne qui vit l'émergence de projets antagoniques: foralistes intransigeants, foralistes libéraux, intégristes traditionnels, carlistes, nationalistes basques de la première génération partagés entre Sabino Arana et Ramon de la Sota, républicains “espagnolistes" mais promoteurs d'une politique linguistique basque (Fermin Herran, Serafin Baroja), partisans d'une nécessaire disparition de la langue basque (Unamuno), libéraux de la bourgeoisie biscayenne défenseurs d'une Espagne centralisée (Echevarria), etc. Bref, Y.K. nous restitue, documents à l'appui, le contexte social et idéologique qui vit la renaissance littéraire basque entre 1888 et 1919. 
Dans le nouveau paysage sociologique qui émergea avec l'industrialisation de la Biscaye, R.M. A. sut éviter l'écueil des nostalgies (Mogel), comme des néologismes et des purismes excessifs (Sabino Arana). Il n'adopta pas une attitude de refus, de repli ou de scepticisme (J.P. Arbelbide, Elysée Reclus, Unamuno), mais s'attacha, avec constance et obstination, à l'élaboration et à la mise en place d'outils susceptibles d'assurer le devenir de l'euskara au sein du nouvel univers basque: enseignement, signalétique, ouvrages didactiques, presse, théâtre, musique, fêtes, le domaine des initiatives de R.M.A. fut vaste et varié.

Y.K. met l'accent sur l'importance des initiatives individuelles face à l'inertie historique des partis politiques au pouvoir, alors que les anciens partis carlistes et intégristes, quoique défenseurs du foralisme, ne menaient aucune promotion en faveur de la pratique du basque au niveau des municipalités et des députations, à de rares exceptions près comme Txomin Agirre ou Julio Urquijo.

R.M.A. se préoccupa de sortir la langue basque du seul usage oral marqué par la grande variété dialectale dans chaque écrivain élaborait ses propres règles d'écriture. Il s'attaqua donc à la question d'une langue basque normalisée tout en évitant l'idéalisation excessive portée à l'extrême par Sabino Arana. L'entreprise était d'autant plus difficile que beaucoup de promoteurs ne vivaient pas dans un environnement sociologique basque (Campion, Azkue, Arana) et qu'il fallait sauvegarder pour le basque, comme pour toute langue d'ailleurs, sa fonction de communication sociale.

Entre ceux qui étaient encore cantonnés dans les légendes, les théories métaphysiques et l'empirisme, et ceux qui avaient fait le choix d'une culture libérale nouvelle, expression du nouveau visage de la culture de masse, les initiatives de R.M.A. furent déterminantes pour l'avenir.

R.M.A. fut de son temps, au sens plein de l'expression. Il eut le souci de connaitre et d'approprier les mouvements et les réalisations en cours en Europe. Il ne vécut pas replié sur sa Biscaye natale et sillonna l'Europe: Paris, Tours, Bruxelles, Cologne, Munich, Berlin, Londres furent les principales étapes de son parcours européen. En conséquence, il est difficile d'accuser R.M.A. de provincialisme. Les modèles culturels et linguistiques qu'il proposa étaient ouverts sur l'avenir.

Manex Goyhenetche 